\title{
Prevalence of diabetes mellitus in a group of women attending "August meeting" at Naze South East Nigeria
}

\author{
Charles U. Osuji ${ }^{1^{*}}$, Bernard A. Nzerem ${ }^{2}$, Chudi E. Dioka ${ }^{3}$, Samuel C. Meludu ${ }^{4}$, \\ Emmanuel I. Onwubuya ${ }^{1}$ \\ ${ }^{1}$ Department of Medicine, Faculty of Medicine, College of Health Sciences, Nnamdi Azikiwe University, Nnewi, Nigeria; \\ *Corresponding Author: ukacharly@yahoo.com \\ ${ }^{2}$ Chapel Group Hospital, Owerri, Nigeria \\ ${ }^{3}$ Department of Chemical Pathology, Faculty of Medicine, College of Health Sciences, Nnamdi Azikiwe University, Nnewi, Nigeria \\ ${ }^{4}$ Department of Biochemistry, Faculty of Basic Medical Sciences, College of Health Sciences, Nnamdi Azikiwe University, Nnewi, \\ Nigeria
}

Received 21 June 2012; revised 19 July 2012; accepted 30 July 2012

\section{ABSTRACT}

Background: For a long time Africa was considered safe from diabetes. However, the International Diabetes Federation predicts an increase in diabetes from 240 million in 2007 to $\mathbf{3 8 0}$ million in 2025 with $80 \%$ of the disease burden in low and middle-income countries including Africa. This study was carried out to assess the prevalence of diabetes mellitus among a group of Nigerian women who had earlier been found to have a high prevalence of overweight/obesity. Methods: 253 women attending the 2009 Meeting were recruited for the study. Blood glucose concentration was measured using ACCUCHEK $^{(R)}$ Advantage glucometer by Roche Diagnostics and diabetes mellitus defined as fasting blood glucose concentration $>7 \mathrm{mmol} / \mathrm{L}$. Results: The population mean age was $53.04 \pm 11.09$ years, diabetics $55.76 \pm 10.77$ years, and nondiabetics $52.84 \pm 11.11$ years $p=0.709 .17(6.7 \%)$ subjects had diabetes. Of the 17 diabetics 10 (3.95\%) were known to have diabetes previously and $7(2.76 \%)$ were diagnosed for the first time. 3 of the 17 diabetics were aged $<50$ years while 14 of the $17(82.3 \%)$ were aged $>50$ years. 11 of the $17(64.7 \%)$ diabetics had blood pressure $>140$ I $90 \mathrm{mmHg}$ while only 54 of the $236(22 \%)$ nondiabetics had blood pressure $>140 / 90 \mathrm{mmHg}$. The mean non fasting blood glucose concentration of the population was $5.83 \pm 2.33 \mathrm{mmol} / \mathrm{L}$, that of diabetics was $11.9 \pm 5.27 \mathrm{mmol} / \mathrm{L}$ and non-diabetics $5.39 \mathrm{mmol} / \mathrm{L} \pm 1.03, \mathrm{p}<0.000$. Of the 10 previously diagnosed to have diabetes only $3(30 \%)$ had fasting blood glucose concen- tration $<7 \mathrm{mmol} / \mathrm{L}$. Diabetes mellitus correlated with age, systolic blood pressure and age correlated with body mass, systolic blood pressure and diastolic blood pressure. Conclusion: The study showed a high prevalence of diabetes with a significant proportion of undiagnosed diabetes and a poor level of control among diagnosed diabetics.

Keywords: Diabetes Mellitus; August Meeting; Igbo-Speaking; Blood Glucose

\section{INTRODUCTION}

The term Diabetes Mellitus describes a metabolic disorder of multiple etiologies characterized by chronic hyperglycemia with disturbances of carbohydrate, fat and protein metabolism resulting from defects in insulin secretion or insulin action or both [1]. Diabetes mellitus is one of the most common chronic diseases in nearly all countries, and continues to increase in numbers and significance, as changing lifestyles lead to reduced physical activity, and increased obesity [2,3]. Diabetes mellitus is a disease of insidious onset and the symptoms, when they eventually appear, do not warrant immediate attention and thus remain undiagnosed at onset and even when diagnosed is often ignored by persons afflicted by it [4].

There have been several previous estimates of the number of persons with diabetes mellitus [5-8]. The prevalence of diabetes mellitus for all age-groups worldwide was estimated to be $2.8 \%$ in 2000 and $4.4 \%$ in 2030 [8]. Estimates of the current and future burden of diabetes mellitus are important in order to allocate community and health resources, and to emphasize the role of life- 
style, and encourage measures to counteract trends for increasing prevalence.

For a long time Africa was considered safe from many of the diseases that are diseases of "affluence" and Dr. Cook had written in 1901 that diabetes mellitus was very uncommon in Africa [9] but rates have been increasing worldwide [10]. From 1959 to the mid-1980s, medical statistics showed that the prevalence rate of diabetes mellitus in Africa was equal to or less than 1.4\% [11]. The International Diabetes Federation predicts that the number of individuals with diabetes mellitus would increase from 240 million in 2007 to 380 million in 2025 with $80 \%$ of the disease burden in low and middle-income countries, [3] which almost all African countries belong to. In Australia the AusDiab study reported in 2000 that $7.4 \%$ of the population aged 25 years and above had diabetes mellitus (type 2 diabetes mellitus in $90 \%$ of cases), and that $50 \%$ of these were undiagnosed [12]. The prevalence seen in Australia is typical of that seen in developed countries unlike the low rates seen in Africa.

Our study came out of the finding by the authors of a high prevalence rate of obesity/overweight (obesity $20.7 \%$ and overweight $38.7 \%$ ) [13], in this group of women during their 2006 "August" Meeting, with the objective of determining the prevalence of diabetes mellitus amongst them, as obesity is associated with high prevalence of diabetes mellitus [14]. In the month of August every year, women married to men of the South East origin usually return to the towns and villages of their husbands irrespective of where they reside in Nigeria to attend the "August" meeting. Initially it used to be mass return but later it became a delegate's conference. During these meetings various development projects are discussed as well as how to achieve the desired goals. Decisions taken at these "August" meetings play important roles in the lives of these towns and villages. For some years the authors had been giving health talks to these women on various aspects of health and the previous year the authors had screened and found very high rates of obesity/overweight in these women which led to the resolve to screen them for diabetes mellitus. Coming from various urban centers across Nigeria it was thought pertinent to study the prevalence of diabetes mellitus in this group of women who are role models in their communities and whose lifestyle may have become westernized as a result of living in an urban centre as urban residence is associated with 4-fold increase in prevalence of diabetes mellitus [15].

Naze is one of the communities that make up OwerriNorth Local Government Area, Imo State of Nigeria. It is a suburb of Owerri, the capital of Imo State which is one of the five states that make-up the South East Zone of Nigeria, inhabited by Igbo speaking people.

\section{SUBJECTS AND METHODS}

A total of 253 women attending the 2009 "August" meeting at Naze, Owerri North Local Government Area, Imo State, were recruited into the study out of a total 350 women that attended the 2009 "August" meeting giving a percentage participation of $72.3 \%$.

Included in the sample were those who were willing to participate and gave informed consent. Also each participant must be a delegate at the 2009 Aladinma Ndom Naze "August" Meeting.

Excluded from the study were those who withheld consent of which there were 45 . Also excluded were those on drugs that affect blood sugar such as steroids, B-blockers, thiazide diuretics of which there were 32, as well as those who were pregnant of which 20 was the number excluded in this group.

Each participant was asked about history of diabetes mellitus and use of drugs and other medication that affect blood glucose like prednisolone, thiazides etc., the subject's age, followed by BP, and weight measurement. Blood pressure was calculated as the average of three measurements taken in a sitting position with an Accosson mercury Sphygmomanometer, with the subject resting for at least 10 minutes, had not drank coffee or smoked cigarettes before the measurement. Body mass was measured using a weighing scale and the subject wearing only light clothing and standing at the centre of the weighing scale and the body mass was read off to the nearest $0.5 \mathrm{~kg}$. Height was not measured because the standiometer broke half way through data collection and could not be immediately replaced.

Non fasting blood glucose concentration was obtained using finger prick with Roche ACCU-CHEK ${ }^{(\mathrm{R})}[16]$ advantage glucometer, Roche Diagnostics. Recent studies have shown that modern handheld glucose measuring devices have excellent technical characteristics and yield results that are similar to reference laboratory methods and besides, various studies $[16,17]$ have reported that capillary glucose measurements are as suitable as venous glucose measurements in the diagnosis and detection of type 2 diabetes mellitus in epidemiological studies and may be cost effective in the implementation of prescreening procedures [16-19]. Those with non fasting blood glucose concentration of more than $7 \mathrm{mmol} / \mathrm{L}$, which was considered abnormal, were asked to report the next morning in a fasting state for fasting blood glucose. There were 41 people in this group and they all complied by the next morning. Diabetes Mellitus was defined as fasting blood glucose concentration $>7 \mathrm{mmol} / \mathrm{L}$. The commercial glucometer used in this study had a mean imprecision of $<4 \%$, with a range of $0.6 \mathrm{mmol} / \mathrm{L}-33.3$ $\mathrm{mmol} / \mathrm{L}$ on fresh capillary blood.

On the day of sampling, the participant's right thumb 
fingertip was first cleansed with sterile alcohol swabs and the arm allowed to hang down briefly to enable blood flow to the fingertips. The side of the finger was then pricked with a lancet (using a new lancet for each participant). This part of the finger was used as it is less sensitive than the tip. Sufficient time was allowed for the drop of blood to form and then sucked onto the test strip (ACCU-CHEK $^{(\mathrm{R})}$ Advantage II strips). The blood glucose level was subsequently read from the glucometer when it is displayed on the glucometer screen.

Statistical analysis was carried out using SPSS version 13 after data that were obtained had been coded and entered into the computer. Student's t test was used for continuous variables, and $\mathrm{X}^{2}$ test was used for categorical variables. In the analyses a p value of $<0.05$ was considered statistically significant

\section{RESULTS}

The mean age of the study population was $53.04 \pm$ 11.09 years, those with diabetes mellitus $55.76 \pm 10.77$ years, and those without diabetes mellitus $52.84 \pm 11.11$ years. There was statistical difference between the ages, $\mathrm{p}<0.000$. Of the 253 women studied 41 had non fasting blood glucose concentration $>7 \mathrm{mmol} / \mathrm{L}$ the previous day, of which 17 were found with blood glucose concentration $>7 \mathrm{mmol} / \mathrm{L}$ after they had done fasting blood glucose concentration the next morning. The prevalence of Diabetes Mellitus was 6.7\% (17/253). Of the 17 with diabetes mellitus 10 (3.95\% prevalence) were known to have diabetes mellitus previously, obtained by asking for history of diabetes mellitus. 7 of the 17 (2.76\% prevalence) were being diagnosed for the first time giving a ratio of 1.4:1 of known diabetes mellitus to newly diagnosed. Only 3 out of the 17 diagnosed to have diabetes mellitus were aged $<50$ years while 14 of the $17(82.3 \%)$ were aged 50 years and above. 11 out of 17 (64.7\%) of those with diabetes mellitus had blood pressure $>140 / 90$ mmHg while only 54 of the 236 (22\%) that did not have diabetes mellitus had blood pressure $>140 / 90 \mathrm{mmHg}$.

The mean non fasting blood glucose concentration of the population was $5.83 \pm 2.33 \mathrm{mmol} / \mathrm{L}$, that of those with diabetes mellitus was $11.90 \pm 5.27 \mathrm{mmol} / \mathrm{L}$ and that of those without diabetes mellitus was $5.39 \pm 1.03$ mmol/L (see Table 1). There was statistical difference between the non fasting blood glucose concentration $\mathrm{p}<$ 0.000. Diabetes mellitus correlated with age, systolic blood pressure and age correlated with body mass, systolic BP, diastolic BP. Table 2 shows age groups, number with diabetes mellitus and prevalence rate. Table $\mathbf{3}$ shows relation between age and diabetes mellitus. Of the 10 previously diabetic only 3 (30\%) had fasting blood glucose concentration of less than $7 \mathrm{mmol} / \mathrm{L}$. Figure 1 shows age groups, number with diabetes mellitus and prevalence rate.

\section{DISCUSSION}

The prevalence of diabetes mellitus in our study was 6.7\%. In different parts of Nigeria and Africa the prevalence of diabetes has been reported to vary from $1 \%$ to $7.4 \%$ [20-24]. The prevalence of $6.7 \%$ compares favorably with the prevalence of $6.8 \%$ obtained by Nyenwe et al. [25]. Though they got a crude prevalence of $6.8 \%$ with a male to female ratio of 1.4:1 which was not statistically significant, but the prevalence rate of their female population compares favorably with our study population. A similar rate of 7.2\% was reported for Lagos Mainland by the National non communicable disease survey [26], but the investigators had a National standardized crude rate of $2.2 \%$ and a prevalence rate of $7.4 \%$ for those aged 45 years and above who live in urban areas. Some urban centers have lower prevalence rates. For example, Ibadan an urban centre south-west of Nigeria had prevalence rate of $1.5 \%$ in the national non communicable disease survey [26]. Although these studies included younger age groups the wide difference observed could not be explained by age only. Those attending August meeting are delegates representing their branches from various urban centers in Nigeria where their families had migrated to for economic reasons. This may explain the similarity in prevalence rates between our study population and those from Lagos and Port Harcourt foremost urban cities in Nigeria. Urbanization brings with it lifestyle changes that

Table 1. Showing means and standard deviation (SD) of age, RBS, SBP, DBP and body mass.

\begin{tabular}{ccccc}
\hline & Diabetic $(\mathrm{n}=17)$ & Non-Diabetic $(\mathrm{n}=236)$ & Total $(\mathrm{n}=253)$ & $\mathrm{p}$ Value \\
\hline Mean Age (years) \pm SD & $55.76(10.77)$ & $52.84(11.11)$ & $53.04(11.09)$ & 0.709 \\
RBS (mMol/L) & $11.90(5.27)$ & $5.39(1.03)$ & $5.83(2.33)$ & $0.000^{*}$ \\
SBP (mmHg) & $150.00(29.79)$ & $128.13(22.39)$ & $129.60(23.53)$ & $0.030^{*}$ \\
DBP (mmHg) & $88.23(15.90)$ & $82.48(12.71)$ & $82.86(12.99)$ & 0.57 \\
Body Mass (Kg) & $66.05(12.86)$ & $68.65(14.26)$ & $68.48(14.16)$ & 0.686 \\
\hline
\end{tabular}

$\mathrm{DM}$ = diabetes mellitus; RBS = random blood glucose; SBP = systolic blood pressure; DBP = diastolic blood pressure; $\mathrm{SD}=$ standard deviation. "Is statistically significant. 
Table 2. Showing age groups, number with $\mathrm{dm}$ and prevalence rate.

\begin{tabular}{ccc}
\hline Age (in yrs) & No with DM & Prevalence Rate (\%) \\
\hline$<40$ & 1 & 0.4 \\
$40-49$ & 2 & 0.8 \\
$50-59$ & 6 & 2.37 \\
$60-69$ & 5 & 2.0 \\
$70+$ & 3 & 1.2 \\
\hline
\end{tabular}

yrs = years; DM = Diabetes mellitus.

Table 3. Showing relation between age and diabetes mellitus.

\begin{tabular}{cccc}
\hline & \multicolumn{3}{c}{ Respondents DM class } \\
\cline { 2 - 4 } & Has no DM & Has DM & Total \\
\hline Respondents age class & & & \\
Less than 50 years & 95 & 4 & 99 \\
Greater than 50 years & 141 & 13 & 154 \\
Total & 236 & 17 & 253 \\
\hline
\end{tabular}

$\mathrm{p}=0.172$.

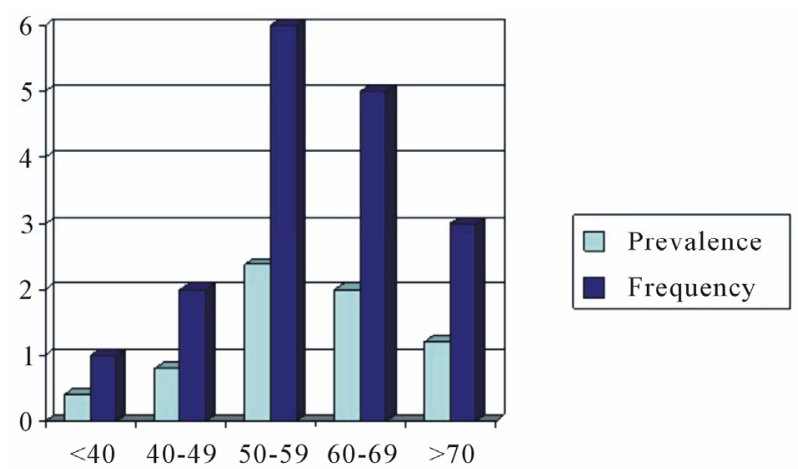

Figure 1. Showing age groups, number with $\mathrm{dm}$ and prevalence rate.

may lead to diabetes mellitus as has been noted in Mauritius where the prevalence of type 2 diabetes mellitus is as high as $10.4 \%$ in Creoles [27]. Mennen et al. [28] had stated that urban lifestyle in Africa is characterized by changes in dietary habits involving an increase in consumption of refined sugars and saturated fats and a reduction in fiber intake.

The prevalence of undiscovered diabetes mellitus in this study was $2.77 \%$ and compares with $2.8 \%$ obtained by Nyenwe et al. [25] in Port Harcourt. Ohwvoriole et al. [29] had earlier reported in 1988 that the prevalence of undiscovered diabetes mellitus was $1.7 \%$ amongst Nigerians living in Lagos Metropolis. The difference between these studies may be explained by modernization and the influence of time. The finding in this study of a high percentage of undiscovered diabetes mellitus in the population calls for intervention in terms of frequent screening and health education on diabetes mellitus and its complications. This is important if the complications are to be ameliorated as diabetes mellitus is a disease of insidious onset, and the symptoms when they eventually appear do not warrant immediate attention and thus remain undiagnosed at onset [4].

It is well known that the prevalence increases with age $[26,30]$ and our study showed that $82.3 \%$ of those with diabetes mellitus were aged 50 years and above. Advancing age has been shown to be an independent risk factor for diabetes mellitus [25]. Johnson [31] and McLarty [32] found that the peak incidence of diabetes mellitus in Nigeria and Tanzania respectively, was after 45 - 50 years of age. The worsening of insulin resistance with age and increasing longevity of diabetic patients due to improved care, all contribute to the rising prevalence of type 2 diabetes mellitus [27,33]. Age related changes in body size, fat distribution and insulin sensitivity contribute to the increased incidence of diabetes mellitus with age, especially of women after menopause. (The Decode Study Group) [34].

In this study we found that in the diabetic population $64.7 \%$ (11/17) had BP > 140/90 mmHg compared to the non-diabetic group. This compares favorably with the finding of Edelman D. et al. [35] though they had studied a population of newly diagnosed diabetes mellitus while our diabetes mellitus population consisted of newly diagnosed and old diabetes mellitus. The explanation of this high prevalence of diabetes mellitus in patients with elevated blood pressure is the well known association of diabetes mellitus and hypertension in the metabolic syndrome.

We also found that control among diagnosed diabetics was very poor. Of the 10 known diabetics only 3 (30\%) had fasting blood glucose of equal or less than $7 \mathrm{mmol} / \mathrm{L}$. This level of control though poor appeared better when compared with the studies of van de Sande et al. [36] and Erasmus et al. [37] who had control levels of $17.6 \%$ and $20.1 \%$ respectively using glycated haemoglobin (HbA1c). It was not possible to measure the glycated hemoglobin in this group which could have given a better insight into the level of control over a period of time and this must have affected the level of control obtained in this study. Suggested reasons for the poor control include poverty which makes it difficult for the sufferer to regularly buy his or her drugs or adhere to recommended diet. Other reasons include lack of awareness of the disease diabetes mellitus, its complications and chronicity, and the belief that diabetes mellitus is caused by the gods and would only come down when it pleases the gods, that is, when the gods have been pacified.

In view of the high prevalence and poor control in this 
study, it is recommended that health awareness campaigns targeted at vulnerable groups be initiated, for the detection of diabetes mellitus using the media (radio and television), health talks at such meetings as "August meeting” and subsequent initiation of appropriate lifestyle changes that may be helpful in reducing the complications of diabetes mellitus. Also clinicians who provide care should be encouraged to screen their patients for diabetes mellitus especially those in the 50 - 59 years age bracket so as to pick them early.

\section{CONCLUSION}

The study showed a high prevalence of diabetes mellitus with a significant proportion of undiagnosed diabetes mellitus and poor level of control among diagnosed diabetics. This calls for concern and the need for screening exercises and health education at various fora regarding non-communicable diseases especially diabetes mellitus.

\section{REFERENCES}

[1] World Health Organization (1999) Definition, diagnosis and classification of diabetes mellitus and its complications. Part 1: Diagnosis and classification of diabetes mellitus. WHO Department of Non Communicable Disease Surveillance, Geneva.

[2] Shaw, J.E., Sicree, R.A. and Zimmet P.Z. (2010) Global estimates of the prevalence of diabetes for 2010 and 2030, Diabetes Research and Clinical Practice, 87, 4-14. doi:10.1016/j.diabres.2009.10.007

[3] Chan, J.C.N., Malik, V., Jia, W., Kadowaki, T., Yajnik, C. S., Yoon K. and Hu, F.B. (2009) Diabetes in Asia: Epidemiology, risk factors, and pathophysiology. The Journal of the American Medical Association, 301, 2129-2140. doi:10.1001/jama.2009.726

[4] Harris, M.I., Klein, R., Welborn, T.A. and Knuiman, M.W. (1992) Onset of NIDDM occurs at least 4 - 7 years before clinical diagnosis. Diabetes Care, 15, 815-819. doi:10.2337/diacare.15.7.815

[5] King, H., Rewers, M. (1993) Global estimates for prevalence of diabetes mellitus and impaired glucose tolerance in adults. Diabetes Care, 16, 157-177. doi:10.2337/diacare.16.1.157

[6] King, H., Aubert, R. and Herman, W. (1998) Global burden of diabetes 1995-2025: Prevalence, numerical estimates and projections. Diabetes Care, 21, 1414-1431. doi:10.2337/diacare.21.9.1414

[7] Amos, A., McCarty, D. and Zimmet, P. (1997) The rising global burden of diabetes and its complications: Estimates and projections to the year 2010, Diabetic Medicine, 14, S1-S85. doi:10.1002/(SICI)1096-9136(199712)14:5+<S7::AID-D IA522>3.3.CO;2-I

[8] Wild, S., Roglic, G., Green, A., Sicree, R. and King, H. (2004) Global prevalence of diabetes: Estimates for the year 2000 and projections for 2030. Diabetes Care, 27, 1047-1053. doi:10.2337/diacare.27.5.1047

[9] Cook, A.R. (1901) Notes on the disease met with in Uganda, Central Africa. The American Journal of Tropical Medicine and Hygiene, 4, 175-178.

[10] King, H. and Rewers, A. (1993) Global estimates for diabetes mellitus and impaired glucose intolerance in adults. WHO Ad Hoc Diabetes Reporting Group. Diabetes Care, 16, 157-177.

[11] Motala, A.A. (2002) Diabetes trends in Africa. Diabetes/Metabolism Research and Reviews, 18, S14-20. doi:10.1002/dmrr.284

[12] Dunstan, D., Zimmet, P., Welborn, T., De Courten, M.P., Cameron, A.J., Sicree, R.A., et al. (2002) The rising prevalence of diabetes and impaired glucose tolerance: The Australian diabetes, obesity and lifestyle study. Diabetes Care, 25, 829-834. doi:10.2337/diacare.25.5.829

[13] Osuji, C.U., Nzerem, B.A., Meludu, S., Dioka, E.C., Nwobodo, E. and Amilo, G.I. (2010) The prevalence of overweight/obesity and dyslipidemia amongst a group of women attending "August” meeting. Nigerian Medical Journal, 51, 155-159.

[14] Aspray, T.J., Mugusi, F., Rashid, S., Whiting, D., Edward, R., Alberti, K.G., et al. (2000) Rural and urban differences in diabetes prevalence in Tanzania: The role of obesity, physical inactivity and urban living. Transactions of the Royal Society of Tropical Medicine and Hygiene, 94, 637-644. doi:10.1016/S0035-9203(00)90216-5

[15] Gill, G., Mbanya, J.C. and Alberti, K.G. (1997) Diabetes in Africa. FSG Communications, Cambridge.

[16] Solnica, B., Naskalski, J.W. and Sieradzki, J. (2003) Analytical performance of glucometers used for routine glucose self-monitoring of diabetic patients. Clinica Chimica Acta, 331, 29-35. doi:10.1016/S0009-8981(03)00079-2

[17] Kruijshoop, M., Feskens, E., Blaak, E.E. and De Bruin, T.W.A. (2004) Validation of capillary glucose measurements to detect glucose intolerance or type 2 diabetes mellitus in the general population. Clinica Chimica Acta, 341, 33-40. doi:10.1016/j.cccn.2003.10.033

[18] Somers, A., Rusford, E., Hassan, M.S. and Erasmus, R.T. (2006) Screening for diabetes mellitus in Belhar, Delft and Mfuleni communities of Cape Town Western South Africa. South African Family Practice, 48, 16.

[19] Owoaje, E.E., Rotimi, C.N., Kaufman, J.S., Tracy, J. and Cooper, R.S. (1997) Prevalence of adult diabetes in Ibadan, Nigeria. East African Medical Journal, 74, 299302.

[20] Rotimi, C.N., Cooper, R.S., Okosun, I.S., Olatunbosun, S.T., Bella, A.F., et al. (1999) Prevalence of diabetes and impaired glucose tolerance in Nigerians, Jamaicans and US blacks. Ethnicity \& Disease, 9, 190-200.

[21] Mbanya, J.C., Ngogang, J., Salah, J.N., Minkoulou, E. and Balkau, B. (1997) Prevalence of NIDDM and impaired glucose tolerance in a rural and an urban population in Cameroon. Diabetologia, 40, 824-829. doi:10.1007/s001250050755

[22] Bakari, A.G., Onyemelukwe, G.C., Sani, B.G., Hassan, S.S. and Aliyu, T.M. (1999) Prevalence of diabetes mel- 
litus in suburban northern Nigeria: Result of a public screening survey. Diabetes International, 9, 59-60.

[23] Motala, A.A., Omar, M.A.K. and Pirie, F.J. (2003) Epidemiology of type 1 and type 2 diabetes in Africa. Journal of Cardiovascular Risk, 10, 77-83. doi:10.1097/00043798-200304000-00002

[24] Rheeder, P. (2006) Type 2 diabetes: The emerging epidemic. South African Family Practice, 48, 20.

[25] Nyenwe, E.A., Odia, O.J., Ihekwaba, A.E., Ojule, A. and Babatunde, S. (2003) Type 2 diabetes in adult Nigerians: A study of its prevalence and Risk factors in Port Harcourt, Nigeria. Diabetes Research and Clinical Practice, 62, 177-185. doi:10.1016/j.diabres.2003.07.002

[26] Akinkugbe, O.O. (1997) Non-communicable disease in Nigeria. Final report of national survey. Federal Ministry Health and Social Services, Lagos, 64-90.

[27] Zimmet, P.Z., McCarty, D.J. and Decouten, M.P. (1997) The global epidemiology of NIDDM and metabolic syndrome. Journal of Diabetes and Its Complications, 11, 60-68. doi:10.1016/S1056-8727(96)00090-6

[28] Mennen, L.I., Mbanye, J.C., Cade, J., Balkau, B., Sharma, S., Chungong, S. and Cruickshank, K. (2000) The habitual diet in rural and urban Cameroon. European Journal of Clinical Nutrition, 54, 150-154. doi:10.1038/sj.ejcn.1600909

[29] Ohwhovoriole, A.E., Kuti, J.A. and Kabiawu, S.I.O. (1988) Casual blood glucose levels and prevalence of undiscovered mellitus in Lagos Metropolis, Nigeria. Diabetes Research and Clinical Practice, 4, 153-158. doi:10.1016/S0168-8227(88)80010-X

[30] Ong, K.L., Cheung, B.M.Y., Wong, L.Y.F., Wat, N.M.S., Tan, K.C. and Lam, K.S. (2008) Prevalence, treatment, and control of diagnosed diabetes in the US national health and nutrition survey 1999-2004. Annals of Epidemiology, 18, 222-229. doi:10.1016/j.annepidem.2007.10.007

[31] Johnson, T.O. (1971) Comparative study of screening methods for diabetes in the elderly Nigerian subject. The West African Medical Journal, 20, 243-246.

[32] McLarty, D.G., Pollitt, C. and Swai, A.B.M. (1991) Diabetes in Africa-Part 1. Practical Diabetes and Digestion, 3, 3-7.

[33] Zimmet, P. (1982) Type 2 (non-insulin dependent) diabetes. An epidemiological overview. Diabetologia, 22, 299-311. doi:10.1007/BF00282581

[34] The Decode Study Group (2003) Age and sex specific prevalence of diabetes and IG regulation in west Asian countries. Diabetes Care, 26, 1770-1780. doi:10.2337/diacare.26.6.1770

[35] Edelman, D., Edwards, L.J., Olsen, M.K., Dudley, T.K., Stat, M., Harris, A.C., Blackwell, D.K., et al. (2002) Screening for diabetes in an outpatient clinic population. Journal of General Internal Medicine, 17, 23-28. doi:10.1046/j.1525-1497.2002.10420.x

[36] van de Sande, M., Dippenaar, H. and Rutten, G. (2009) The relationship between patient education and glycemic control in South African Township. Primary Care Diabetes, 1, 87-91. doi:10.1016/j.pcd.2007.04.007

[37] Erasmus, R.T., Blanco Blanco, E., Okesina, A.B., Gqwet, Z. and Matsha, T. (1999) Assessment of glycemic control in stable type 2 black South African diabetics attending a peri-urban clinic. Postgraduate Medical Journal, 75, 603606. 